\title{
Ramadan fasting during Covid-19 pandemic
}

\section{Ali Tootee ${ }^{1} \cdot$ Bagher Larijani $^{2}$}

Published online: 30 April 2020

(C) Springer Nature Switzerland AG 2020

The ritual of fasting, which includes complete refraining from food or drink, dates back to antiquity, and is observed in different religions such as Islam and Judaism. Islamic fasting is observed during the lunar month of Ramadan every year, and approximately 2 billion Muslims practice it all across the globe. [1] During Ramadan, all healthy Muslim adults (without any particular adverse health condition) need to fast from dawn to dusk and abstain from eating, drinking, smoking, intercourse, and several other activities. This can potentially last for more than $18 \mathrm{~h}$ a day depending on the latitude. [2] Nonetheless, there are several exemptions to this divine obligation, and travelers, menstruating women and those with certain diseases (or at increased risk for contracting a disease) can be exempted from the obligation. [3] For many Muslims, depending on the school of Islam they follow, these certain diseases or increased risks should be officially announced as Fatwas or religious edicts. Nonetheless, ultimately, these decisions need to be made on an individual basis according to the physicians' recommendations. In some schools of Islam, such Fatwas are issued through an intricate collaborations amongst high-ranking Islamic jurisprudence scholars, academics, and medical practitioners on a virtually annual basis prior to the commencement of the holy month. $[1,4,5]$

Health benefits of different patterns of fasting are very diverse and are described in details in the literature. [6] Initially, it was believed that reduction in the production of oxygen free radicals is the sole responsible mechanism of the wide range of health benefits observed in fasting. [6] Later, solid evidence emerged from comprehensive studies demonstrated that not all health benefits of different fasting regimens (such as

Bagher Larijani

larijanib1340@gmail.com

1 Diabetes Research Center, Endocrinology and Metabolism Clinical Sciences Institute, Tehran University of Medical Sciences, Tehran, Iran

2 Endocrinology and Metabolism Research Center, Endocrinology and Metabolism Clinical Sciences Institute, Tehran University of Medical Sciences, Tehran, Iran intermittent fasting) can be attributed to reduced free-radical production. [7] Recently, it was brought to light that fasting can activate certain adaptive cellular responses which can improve glucose regulation, increase resistance to stress, and suppress inflammatory reactions. [8] Today, it is demonstrated that fasting can activate different cellular pathways which foster intrinsic defense mechanisms against metabolic and oxidative stress, and this can lead to removal of damaged cells and molecules. [9]

Decisive evidence emerged from numerous in-depth studies have clearly demonstrated that fasting can produce therapeutic effects in many noncommunicable disorders such as obesity, diabetes, cardiovascular disease, cancers, and neurodegenerative diseases. [8] Fasting can also play a protective role against aging. A comprehensive meta-analysis study which was recently conducted has demonstrated that the average life expectancy can significantly increase by fasting. [10] Moreover, fasting can improve physical composition, function, and endurance. [11, 12] Fasting can also enhance cognitive functions in terms of spatial memory, associative memory and working memory, and can reverse neurotoxic effects of obesity, diabetes, and neuroinflammation. [13] This dietary intervention can even facilitate amelioration of cognitive deficits in traumatic brain injury. [14] Moreover, results of an study we conducted in 2012 demonstrated that fasting has a remarkable influence in promotion of psychologic health and regulation of sleep pattern. [15] These evidence and similar findings indicate that the effects of Ramadan Fasting are not merely confined those related to refraining from eating and drinking, and they include a diverse range of physical, psychological, and spiritual health.

Considering diverse benefits of fasting, this ancient dietary alternation has been recently bought to light as a therapeutic clinical intervention. In clinical settings, caloric restriction and fasting has been documented to improve several cardiometabolic risk factors in nonobese humans. [16] This healing effect is medicated through a wide range of mechanisms such as modification of blood pressure, resting heart rate, levels of high-density and low-density lipoprotein (HDL and LDL) cholesterols, triglycerides, glucose, and insulin concentration, 
and insulin resistance. [16-18] Besides, atherosclerosisassociated systemic inflammation and oxidative stress markers can be significantly reduced in fasting. [19, 20] Fasting can also protect individuals against malignancies. Several detailed studies have demonstrated that different fasting regimens can decrease the rate of occurrence of spontaneous tumors in aged animals. Moreover, growth of induced tumors may be suppressed in fasting while their sensitivity to chemotherapy and radiotherapy is markedly increased. [21-23] It is also well-documented that excessive energy intake can increase the risks of stroke, Alzheimer's disease, and Parkinson's disease. Astonishingly, fasting can delay or even reverse development and progress of such neurological defects. [24] This can be attributed to several mechanisms such as strengthening mitochondrial function, stimulation of autophagy, increasing production of neurotrophic-factor, activation of antioxidant defense mechanisms, and acceleration of DNA repair processes. [25] By means of the aforementioned mechanisms, fasting can also alleviate symptoms of asthma, multiple sclerosis, and arthritis. [26-28]

Notwithstanding all documented health benefits of fasting, in this Ramadan, there has emerged some uncertainty as to whether fasting is safe during the current outbreak. Millions of people have contracted COVID-19, hundreds of thousands have develop severe illness, and tens of thousands have perished. [29] This time, arguably for the first time in the modern era, jurisprudence scholars, academics, and medical practitioners all seem perplexed as to whether temporary starvation and dehydration might increase the risk of contracting the circulating corona virus. Unfortunately, there is a paucity of academic literature on the effects of Ramadan Fasting. Although there exists a considerable body of literature on the benefits of intermittent fasting, [1] most such research have focused on mere calorie restriction, and have not taken the potential effects of simultaneous dehydration and dryness of airways into consideration. [30] This makes a substantial difference, and, therefore, the findings of studies on different patterns of intermittent fasting cannot be simply generalized to Ramadan Fasting. Moreover, it is sometimes claimed that dry mouth and throat caused by Ramadan Fasting may increase the risk of contracting the virus. Although this belief has been refuted by major health and religious authorities, the evidence produced in this regard are neither reliable nor incontrovertible. [30] Therefore, it appears that scientific studies exclusively carried on Ramadan Fasting constitute the only available source of information for jurisprudence scholars, academics, and medical practitioners.

As regards immunological changes, It is documented that Ramadan Fasting does not lead to any immunological malfunction. [31] On the contrary, there exist a considerable body of evidence that suggest Ramadan Fasting can strengthen the immune system against infections. This immunoprotective effect, in part, may be attributed to increased serum levels certain immunoglobulins such as IgA. [32] Moreover, levels of some elements of the complement system (such as $\mathrm{C} 4$ ) are demonstrated to increase during Ramadan Fasting, thereby protecting individuals against a wide range of microorganisms. [33] Many such immunoprotective effects are also confirmed by clinical evidence. For instance, Lahdimawan et al. have demonstrated that Ramadan Fasting can play a protective role against tuberculosis, and can minimize the risk of the infection in healthy individuals. [34] Nonetheless, one should be very cautious in interpretation of such results. In fact, several studies have brought some unfavorable consequences of fasting into light. For instance there is some evidence suggesting that Ramadan Fasting can decrease IgG levels. [34] Moreover, in patients with diabetes, it is demonstrated that Ramadan Fasting can lead to an increased risk of infection. [35]

Notwithstanding all aforementioned evidence in favor or against the practice of Ramadan Fasting in terms of infection risk, there is no conclusive evidence to acknowledge or refute increased susceptibility of fasting individuals to contracting Covid-19 infection. Similarly, no evidence has emerged indicating that drinking water during daytime can prevent corona virus infection in healthy individuals. [30] Inconclusive as the situation may appear, the current pandemic has led to formation of a individual-based approach to jurisprudence dilemmas in some schools of Islam. Accordingly, many academics, physicians, and jurisprudence scholars have arrived at the conclusion that the risk of infection (and development of possible life-threatening consequences) should be considered on an individualized basis. Accordingly, the elderly and the frail should refrain from fasting lest potential deadly consequences. Nonetheless, old persons in quarantine who are confident that they are not exposed to the virus can fast provided that they consume a balanced diet and have adequate rest. [36] In terms of healthcare professionals, it is advised that they should assess their own situation on a daily basis, and they could break their fasting if they cannot perform their duties or perceive themselves at a great risk. All aforementioned recommendations and advises need to be taken into consideration by both the persons intending to fast and the physicians in charge.

In this regard, an official declaration has recently been published by the Academy of Medical Sciences (AMS) of Islamic Republic of Iran. In this official announcements, it is recommended that healthy individuals younger than 65 can observe Ramadan Fasting provided that they follow certain precautions. [37] These precautions include: strict adherence to all infection control guidelines and procedures, proper hydration in non-fasting hours, humidification of indoor air, consumption of a balanced diet rich in fruits and vegetables, and avoiding dry and hot environments. This assembly which was consisted of a great number of high-ranking physicians, scientists, theologists, and, jurisprudence scholars, has also recommended that considering high incidence of 
hypertension, diabetes, and cardiovascular disease in persons older than 65 , they should refrain from fasting lest possible dire consequences. However, ultimately, this decision should be made by any individual patient himself according to his physicians' advise. In regards with patients with diabetes who are younger than 65 , according to this announcement, they can only observe fasting provided that their diabetes is perfectly controlled (with $\mathrm{HbA} 1 \mathrm{c}<7$ ) through proper lifestyle modifications and medications. This official document has also decided that fasting should be prohibited in patients with history of organ transplantation (with the exception of corneal transplantation). In regards with those infected with the virus, the assembly announced that they should refrain from fasting for several weeks after complete recovery. It is noteworthy that these recommendations are all in complete accordance with the highly credible scientific evidence AMS members had previously published on the subject. For instance, in a comprehensive research on the subject which was published by members on the assembly in 2010, authors had contended that although Ramadan fasting is generally safe and wholesome for healthy individuals, those with certain diseases and adverse health conditions should seek their physicians' advice in this regard. [38]

In conclusion, this year, it appears that there exists a widespread confusion surrounding the practice of Ramadan Fasting amid Covid-19 pandemic, and jurisprudence scholars, scientists, and physicians are all similarly perplexed as to whether or not fasting is safe. In some schools of Islam, it is even contended that fear and risk of contracting the infection does not justify non-adherence of followers to fasting which is considered as one of the four fundamental pillars of faith in Islam. [30] Accordingly, several different (and sometimes contradictory) guidelines, fatwas, and recommendations have emerged on the subject. Therefore, it would be feasible to contend that the ultimate decision in this regard should be made by each individual person (according to the fatwas) based on the recommendations of the physicians in charge.

\section{References}

1. Khan, M.H. and R. Al-Lehebi, Respiratory disease and Ramadan. The Lancet Respiratory Medicine, 2020, Respiratory disease and Ramadan.

2. Larijani B, Zahedi F, Sanjari M, Amini MR, Jalili RB, Adibi H, et al. The effect of Ramadan fasting on fasting serum glucose in healthy adults. Med J Malays. 2003;58(5):678-80.

3. Shadman, Z., et al., Ramadan major dietary patterns. Iran Red Crescent Med J, 2014. 16(9).

4. Khoshniat M, Shadman Z, Larijani B. Ramadan fasting and diabetes. Payesh (Health Monitor). 2013;12(1):35-44.

5. Larijani $\mathrm{B}$, Anaraki FZ. Islamic principles and decision making in bioethics. Nat Genet. 2008;40(2):123-3.

6. Weindruch R, Sohal RS. Caloric intake and aging. N Engl J Med. 1997;337(14):986-94.
7. Longo VD, Mattson MP. Fasting: molecular mechanisms and clinical applications. Cell Metab. 2014;19(2):181-92.

8. de Cabo R, Mattson MP. Effects of intermittent fasting on health, aging, and disease. N Engl J Med. 2019;381(26):2541-51.

9. Mattson MP, Moehl K, Ghena N, Schmaedick M, Cheng A. Intermittent metabolic switching, neuroplasticity and brain health. Nat Rev Neurosci. 2018;19(2):63-80.

10. Swindell WR. Dietary restriction in rats and mice: a meta-analysis and review of the evidence for genotype-dependent effects on lifespan. Ageing Res Rev. 2012;11(2):254-70.

11. Chaix A, Zarrinpar A, Miu P, Panda S. Time-restricted feeding is a preventative and therapeutic intervention against diverse nutritional challenges. Cell Metab. 2014;20(6):991-1005.

12. Moro T, Tinsley G, Bianco A, Marcolin G, Pacelli QF, Battaglia G, et al. Effects of eight weeks of time-restricted feeding (16/8) on basal metabolism, maximal strength, body composition, inflammation, and cardiovascular risk factors in resistance-trained males. J Transl Med. 2016;14(1):290.

13. Wahl D, Coogan S, Solon-Biet S, de Cabo R, Haran J, Raubenheimer D, et al. Cognitive and behavioral evaluation of nutritional interventions in rodent models of brain aging and dementia. Clin Interv Aging. 2017;12:1419-28.

14. Liu Y, Wang R, Zhao Z, Dong W, Zhang X, Chen X, et al. Shortterm caloric restriction exerts neuroprotective effects following mild traumatic brain injury by promoting autophagy and inhibiting astrocyte activation. Behav Brain Res. 2017;331:135-42.

15. Khoshniat Nikoo M, Shadman Z, Larijani B. Ramadan fasting, mental health and sleep-wake pattern. ISMJ. 2012;15(2):137-50.

16. Most J, Gilmore LA, Smith SR, Han H, Ravussin E, Redman LM. Significant improvement in cardiometabolic health in healthy nonobese individuals during caloric restriction-induced weight loss and weight loss maintenance. Am J Physiol-Endocrinol Metab. 2018;314(4):E396-405.

17. Wan R, Camandola S, Mattson MP. Intermittent food deprivation improves cardiovascular and neuroendocrine responses to stress in rats. J Nutr. 2003;133(6):1921-9.

18. Fontana L, Meyer TE, Klein S, Holloszy JO. Long-term calorie restriction is highly effective in reducing the risk for atherosclerosis in humans. Proc Natl Acad Sci. 2004;101(17):6659-63.

19. Johnson JB, Summer W, Cutler RG, Martin B, Hyun DH, Dixit $\mathrm{VD}$, et al. Alternate day calorie restriction improves clinical findings and reduces markers of oxidative stress and inflammation in overweight adults with moderate asthma. Free Radic Biol Med. 2007;42(5):665-74.

20. Harvie M, Wright C, Pegington M, McMullan D, Mitchell E, Martin B, et al. The effect of intermittent energy and carbohydrate restriction v. daily energy restriction on weight loss and metabolic disease risk markers in overweight women. Br J Nutr. 2013;110(8): $1534-47$.

21. Mattison JA, Colman RJ, Beasley TM, Allison DB, Kemnitz JW, Roth GS, et al. Caloric restriction improves health and survival of rhesus monkeys. Nat Commun. 2017;8:14063.

22. Meynet O, Ricci J-E. Caloric restriction and cancer: molecular mechanisms and clinical implications. Trends Mol Med. 2014;20(8):419-27.

23. Nencioni A, Caffa I, Cortellino S, Longo VD. Fasting and cancer: molecular mechanisms and clinical application. Nat Rev Cancer. 2018;18(11):707-19.

24. Arnold SE, Arvanitakis Z, Macauley-Rambach SL, Koenig AM, Wang HY, Ahima RS, et al. Brain insulin resistance in type 2 diabetes and Alzheimer disease: concepts and conundrums. Nat Rev Neurol. 2018;14(3):168-81.

25. Menzies FM, Fleming A, Caricasole A, Bento CF, Andrews SP, Ashkenazi A, et al. Autophagy and neurodegeneration: pathogenic mechanisms and therapeutic opportunities. Neuron. 2017;93(5): 1015-34. 
26. Müller H, de Toledo FW, Resch K-L. Fasting followed by vegetarian diet in patients with rheumatoid arthritis: a systematic review. Scand J Rheumatol. 2001;30(1):1-10.

27. Jensen M, et al. Diet-induced weight loss in obese children with asthma: a randomized controlled trial. Clin Exp Allergy. 2013;43(7):775-84.

28. Choi IY, Piccio L, Childress P, Bollman B, Ghosh A, Brandhorst S, et al. A diet mimicking fasting promotes regeneration and reduces autoimmunity and multiple sclerosis symptoms. Cell Rep. 2016;15(10):2136-46.

29. Fontanarosa, P.B. and H. Bauchner, COVID-19-looking beyond tomorrow for health care and society. JAMA, 2020.

30. Amir, K.A., Ramadan during COVID-19: What clerics and health experts say, in Gulf News [Internet]. 2020.

31. Develioglu ON, Kucur M, Ipek HD, Celebi S, Can G, Kulekci M. Effects of Ramadan fasting on serum immunoglobulin $\mathrm{G}$ and $\mathrm{M}$, and salivary immunoglobulin a concentrations. J Int Med Res. 2013;41(2):463-72.

32. Khazaei, H.A., M. Bokaeian, and A. Jalili, The effect of fasting on the immune system of athletes during holly Ramadan. Zahedan $\mathrm{J}$ Res Med Sci, 2014. 16(6).
33. Heydarpour, A., et al., The effect of Ramadan fasting on blood biochemical factors related to immune system in summer 2015.

34. Lahdimawan, A., et al., Effect of Ramadan fasting on the ability of serum, PBMC and macrophages from healthy subjects to kill $M$. tuberculosis. IOSR Journal of Pharmacy and Biological Sciences (IOSR-JPBS), 2014. 9(1): p. 24-9.

35. Bragazzi NL, Briki W, Khabbache H, Rammouz I, Mnadla S, Demaj T, et al. Ramadan fasting and infectious diseases: a systematic review. J Infect Develop Countries. 2015;9(11):1186-94.

36. Al-Seestani, A.-S.A. Ayatollah Sistani's Fatwa on Fasting during Ramadan in the Shadow of Coronavirus. 2020 [cited 20202020 , April 15]; Available from: http://ijtihadnet.com/ayatollah-sistanisfatwa-on-fasting-during-ramadan-in-the-shadow-of-coronavirus/.

37. Marandi, Ramadan Fasting amid Corona Virus Pandemic in Academy of Medical Sciences 2020.

38. Azizi F. Islamic fasting and health. Ann Nutr Metab. 2010;56(4): 273-82.

Publisher's note Springer Nature remains neutral with regard to jurisdictional claims in published maps and institutional affiliations. 